\title{
Heat Transfer Fluid Temperature Control in a Thermoelectric Solar Power Plant
}

\author{
Lourdes A. Barcia ${ }^{1}$, Rogelio Peon ${ }^{2}$, Juan Díaz ${ }^{3, *}$, A.M. Pernía ${ }^{3}$ and Juan Ángel Martínez ${ }^{3}$ \\ 1 Normagrup Technology S.A., 33420 Llanera, Asturias, Spain; lurdesalbar@gmail.com \\ 2 Grupo TSK PCyT de Gijón, 33203 Gijón, Spain; rogelio.peon@tsk.es \\ 3 Department of Electrical Engineering, University of Oviedo, 33203 Gijón, Asturias, Spain; \\ amartinp@uniovi.es (A.M.P.); jamartinez@uniovi.es (J.A.M.) \\ * Correspondence: jdiazg@uniovi.es; Tel.: +34-98-5182564
}

Received: 10 May 2017; Accepted: 21 July 2017; Published: 25 July 2017

\begin{abstract}
Thermoelectric solar plants transform solar energy into electricity. Unlike photovoltaic plants, the sun's energy heats a fluid (heat transfer fluid (HTF)) and this, in turn, exchanges its energy, generating steam. Finally, the steam generates electricity in a Rankine cycle. One of the main advantages of this double conversion (sun energy to heat in the HTF-Rankine cycle) is the fact that it facilitates energy storage without using batteries. It is possible to store the heat energy in melted salts in such a way that this energy will be recovered when necessary, i.e., during the night. These molten salts are stored in containers in a liquid state at high temperature. The HTF comes into the solar field at a given temperature and increases its energy thanks to the solar collectors. In order to optimize the sun to HTF energy transference, it is necessary to keep an adequate temperature control of the fluid at the output of the solar fields. This paper describes three different algorithms to control the HTF output temperature.
\end{abstract}

Keywords: thermal power plant; heat transfer fluid (HTF); process modeling; temperature control

\section{Introduction}

The current increasing demand of energy requires the use of clean and renewable energies in order to prevent global warming. As it is well known, clean energies take advantage of different natural resources, such as wind, sun, tides, waves, geothermal, and different biofuels. The Kyoto Protocol evinces the world's concern about using non-pollutant energies, regardless of the full compliance of it. The EU has set different goals for 2020: a 20\% reduction of greenhouse gas emissions, $20 \%$ of the energy has to be produced using renewable energies, and a 20\% efficiency improvement (20/20/20 goal [1]). Whatever the result, the world investment in this field was about 256,000 $€$ in 2015, and it is expected to be increased in the near future [2].

One of the main drawbacks of these energies is their availability: as soon as they are generated, they have to be consumed, and the regulation is more complex than that in traditional energies, since natural resources are certainly unforeseeable. In this way, technology has evolved in such a way that different energy storage techniques have been proposed: chemical methods (batteries), flywheels-in which kinetic energy is stored-magnetic energy systems, compressed air storage, thermal storage, pumped hydro, and many others [3,4]. If renewable generation is combined with a clean storage method, the aforementioned problems are overcome, since it will be possible to generate energy even when the natural source is not available. The best example is the sun: it is evident that, during the night, it is impossible to obtain energy from it; however, it is possible to store the energy generated during sunny periods and consume it during the night. This is the case of solar thermal plants, such as the one that is the goal of this work: "La Africana", located in Córdoba, in the south of Spain (Figure 1). 
In this plant, the energy of the sun is transferred to the HTF (heat transfer fluid), and this fluid-usually a sort of oil-returns the energy back to two different systems $[5,6]$ :

- $\quad$ The electricity generation system, based on the Rankine cycle: the HTF gives back its energy to the water, in order to produce steam.

- $\quad$ The energy storing system: the HTF returns the acquired energy in order to heat and melt salts. These salts are stored in special containers and maintain their calorific energy during the whole day. Thus, in those periods in which solar radiation is not available, the molten salts return back the energy to the HTF. The system is a thermal energy storage (TES) one.

The TES structure is composed by two molten salt reservoirs: one of them, named the hot tank, stores molten salts after receiving the thermal energy: this one is refilled during sunny hours, as it was previously exposed. Its temperature is around $400^{\circ} \mathrm{C}$. The other tank stores cold (around $300{ }^{\circ} \mathrm{C}$ ) salts, in a liquid state: In this tank, the salts are returned after yielding their energy to the HTF.

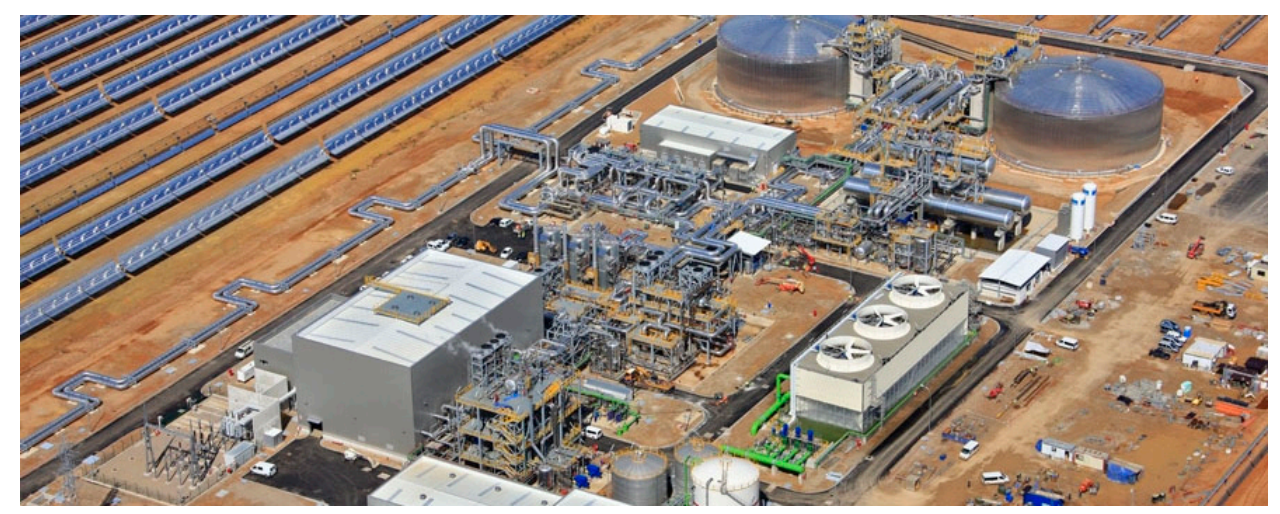

Figure 1. General view of "La Africana". Hot and cold tanks are shown at the top, with the heat exchanger in between. The solar collectors are located at the left of the image.

In "La Africana", it is possible to store energy to supply electricity for $7.5 \mathrm{~h}$; a more detailed description can be found in [7]. This plant uses well-known parabolic trough collectors.

In order to obtain the best efficiency in the whole process, it is essential to maintain the HTF temperature and flow as high as possible-always under the maximum limits-at the solar field output. The major problem is that solar radiation is unpredictable, so it is necessary to implement an adequate feedback loop to maximize the energy exchange from the sun to the HTF. In addition, to make things more complex, the HTF temperature takes a long time to react, since the fluid has to go through the solar field; in other words, there is an important delay between control action and the response of the system. This paper deals with the HTF control temperature and presents three different algorithms to maintain the HTF temperature at a defined set point.

\section{Material and Methods}

In thermal solar plants, control is one of the most delicate issues to optimize their behavior. There are different subsystems within these plants that need adequate control to keep parameters within certain values: control of the mirror positions, control of the thermal energy storage, control of the steam generator, control of the temperature of the HTF, and so on. In fact, in order to optimize the Rankine cycle efficiency, it is essential to keep the HTF temperature as high as possible, below the maximum limits, of course.

In order to propose and validate different control algorithms for the HTF temperature, it is necessary to model the solar field and the energy exchange process, and set the possible variables and inputs/outputs to the system. The model of the solar field has already been proposed in [5], and validated with real data. Moreover, a proportional integral derivative (PID) controller has also 
been proposed. The process has been modelled using MATLAB-SimuLink R2012b. The process is summarized in Figure 2.

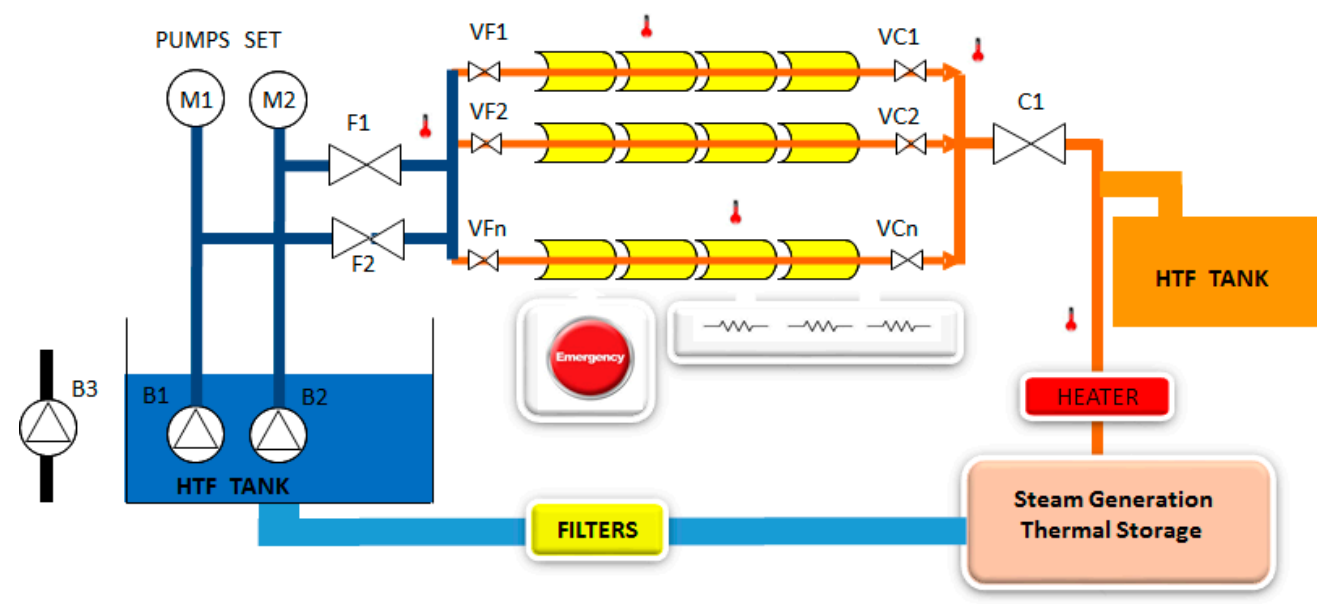

Figure 2. Simplified scheme of the heat transfer fluid (HTF) heating process.

The HTF is pumped into the solar field from a cold tank, through a set of pumps (B1 and B2), which set the HTF speed; valves F1, VF1, VC1, and C1 control the mass flow. The HTF enters the solar field and gets the energy from the sun. The process is continuously monitored: temperature, pressure, ambient temperature, and so on. At the solar field output, the HTF yields its energy to the steam generation and the thermal storage systems. The cold HTF goes back to the cold tank, through a filtering stage, and the process is reinitiated. The goal is to fix the HTF temperature to a predefined set point and to ensure that it does not exceed or fall below the thresholds. For instance, if the solar radiation is not providing enough energy, the HTF obtains the thermal energy from gas heaters and, on the contrary, if the energy is too high, it is necessary to move the mirrors, in order to reduce the HTF heating. Additionally, the sun radiation and the mirror positions, the HTF input temperature, and the dirtiness in the mirrors (and absorbing pipes) affect the process as well.

The solar field was completely modeled including not only the absorber pipes included in the solar collector elements but also the large headers that introduce the HTF into the solar field (cold headers) and collect the HTF at the output of the solar field to transport it to the TES and to the steam generator system (SGS) (heat headers). Although other solar plant models can be found in the literature [8,9], they are much more complex that the one presented in [5] and, for that reason, they are not suitable to be used in a real plant.

Figure 3 shows the solar field model that has been deeply developed and explained in [5]:

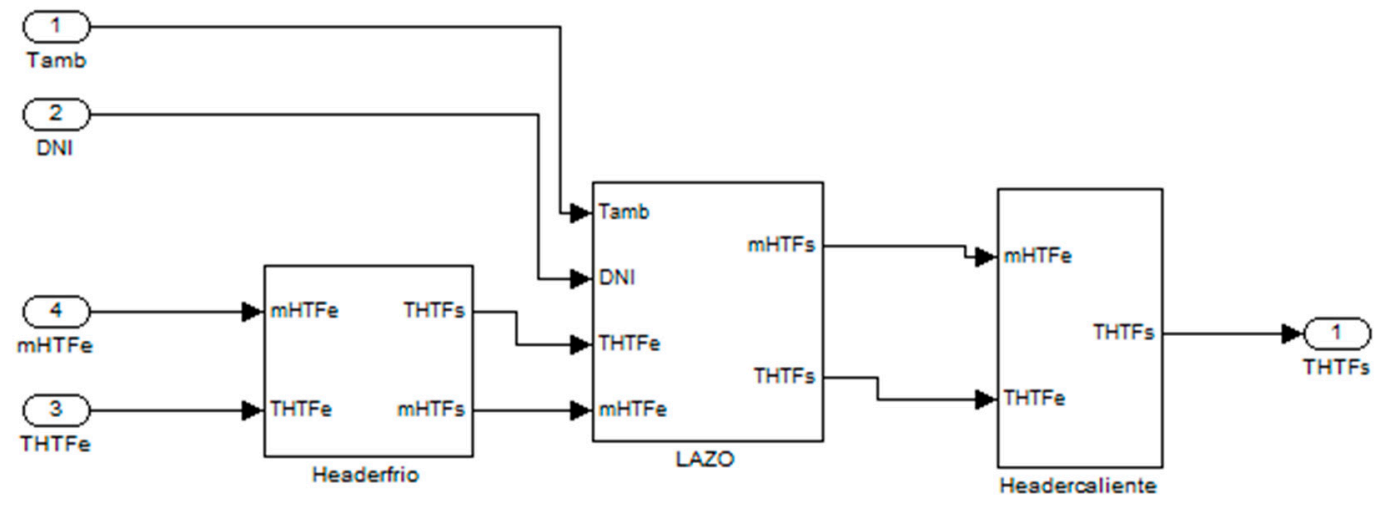

Figure 3. Solar field dynamic model. 
The inputs are the ambient temperature (Tamb), the direct normal irradiation (DNI), the HTF mass flow in the solar field (mHTFe), and its temperature at the input of the solar field (THTFe); the output is the HTF temperature at the outlet of the solar field (THTFs). In order to control this temperature, it is necessary to modify the mass flow: the greater the mass flow, the lower the temperature at the output of the solar field. In other words, if the same energy (sun) is used with a greater amount of fluid, the temperature rise will be lower.

This model was validated with a PID controller. The results obtained evinced that this algorithm is suitable provided there are no sharp changes in the input variable, the solar radiation. This sort of disturbance may occur when the sky is full of clouds that suddenly disappear. As aforementioned, the system is very slow, and its response has very important delays. These delays cause overshoots and spikes in the HTF temperature that can ruin the HTF.

\subsection{Design of the Controllers}

In order to optimize the HTF temperature control, other algorithms were tested using the same model as above.

\subsubsection{PID Feed-Forward}

To overcome the PID problems, a modification of this algorithm is proposed and it is no other than a feed-forward stage inclusion. According to Figure 4, this algorithm takes into account not only the set point for the HTF output temperature, but also the sun irradiation - by means of direct normal irradiation (DNI) and the mirror angles-the HTF input temperature, and the ambient temperature. The aim of this algorithm is to predict the mass flow needed for the system, correcting the one calculated using only the reference (set point, SPTHTF) and the output temperature. In other words, the mass flow needed to obtain the desired temperature is now recalculated, considering more process parameters. This is done by including a new block (mHTF_calc PROCESS) that calculates the optimal mass flow, taking into account the values of a set of input variables at any given time. Thus, it is possible to have the pumps ready to change the mass flow even before the disturbances can affect the process output. By doing so, large changes appearing in the PID controller are avoided, since action takes place without having to wait for the value of the HTF temperature to be present at the output of the solar field.

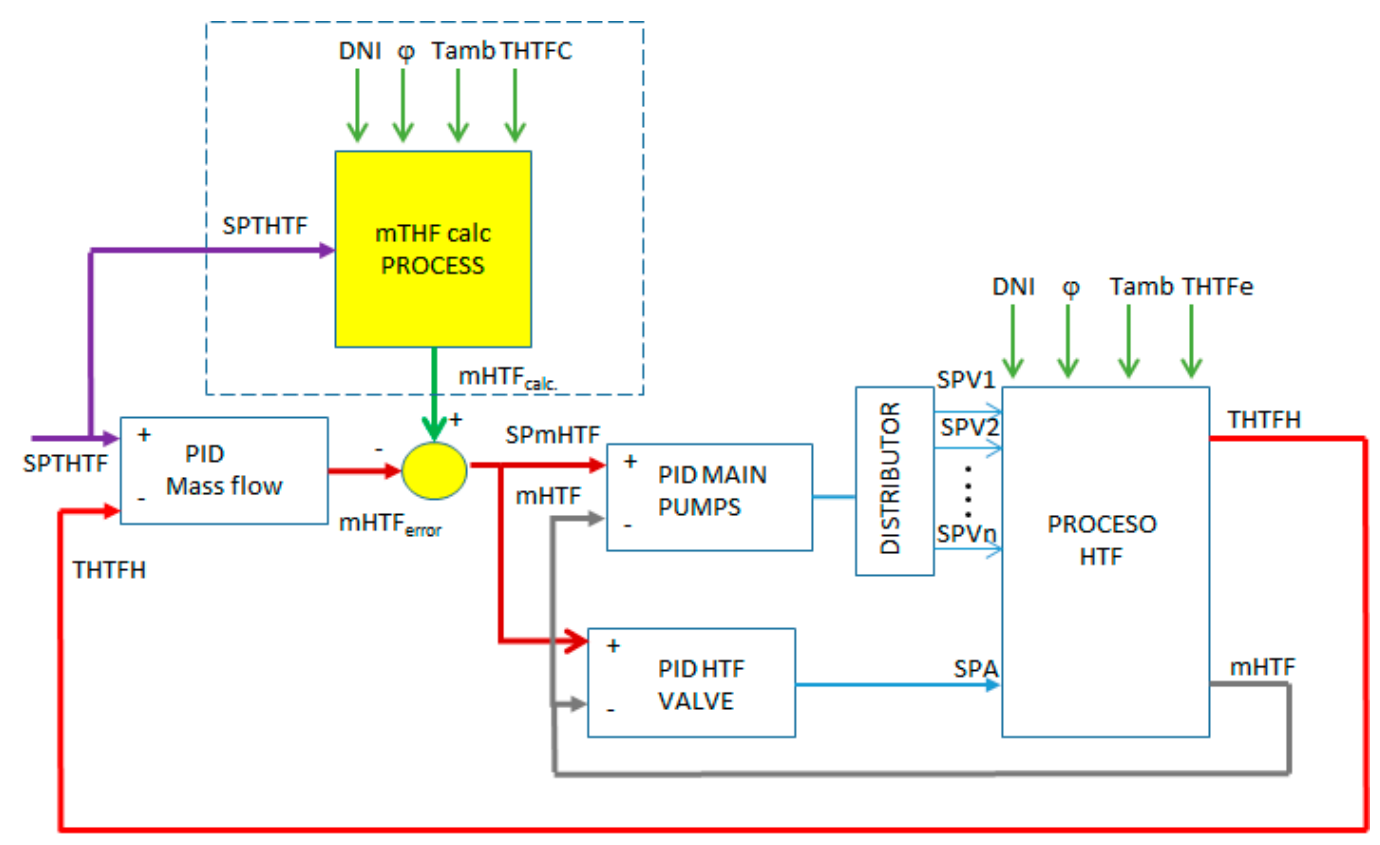

Figure 4. Block diagram of the process, with the feed-forward implemented. 
The equation included in block (mHTF_calc PROCESS) obtains the mass flow that the system should have by relating it to known input variables and to the set point for the output variable (SPTHTFh):

$$
\dot{m}_{H T F}=\frac{Q_{u t i l}}{\left(T_{H T F h}-T_{H T F C}\right) \cdot C p}
$$

where $Q_{u t i l}$ is the calorific energy that reaches the thermal fluid after considering all the losses, due to different reasons: dirt on the mirrors, for instance. Moreover, the incident angle of the solar radiation on the mirrors, shadows, convection, radiation, and conduction thermal exchanges in the absorber tubes have also been taken into account $[10,11]$. The variable named $T_{H T F h}$ is the thermal fluid temperature at the output of the solar field, $T_{H T F C}$ is the thermal fluid temperature just before entering the solar field, $T_{H T F h}$ is the temperature of the thermal fluid at the output of the solar field, $\phi$ represents the mirrors angle, $m_{H T F}$ is the HTF mass flow, and $C p$ is the specific heat at constant pressure of the thermal fluid. This parameter depends on the fluid temperature. Even when Qutil has been calculated in static mode, the SF model takes into account the inertia of the process by means of considering all of the fluid volume, as well as the total length of the absorber tubes and headers. For that, the model was created by the union of blocks in series that models all the absorber pipes and the headers.

\subsubsection{Adaptive-Predictive-Expert Control (ADEX)}

Adaptive-predictive-expert control (ADEX) combines two types of control: an adaptive-predictive one (AP) and an expert control. The adaptive-predictive (AP) control aims to make the process output follow a desired path or trajectory [12]. The most relevant operating blocks of an adaptive-predictive control can be seen in Figure 5 [13].

Predictive models provide the control signal required to make the output follow the values produced by a driver block, which generates a simple path for the process output to reach the set point. If predictions were always right, the driver block and the predictive model would suffice to control a process. Unfortunately, dirt, aging, etc., can modify the system and the process dynamics, making the predictions wrong. This problem can be overcome by including an adaptive mechanism that introduces the required adjustments in the predictive model by notifying the driver block about trends and prediction errors. This gives rise to an adaptive-predictive model, which reduces and fixes prediction errors in a stable and efficient way.

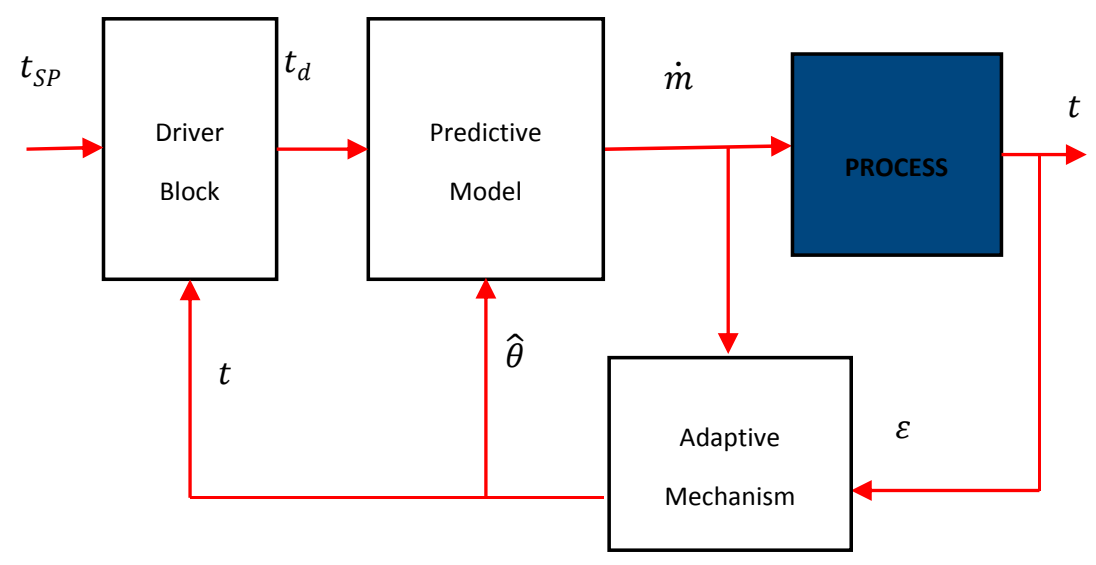

Figure 5. Adaptive-predictive control scheme block diagram.

In applications such as the one considered in this paper, the process dynamics defined in the predictive controller can be represented by means of a multi-input single-output (MISO) difference equation:

$$
y(k)=\sum a_{i}(k) y(k-i)+\sum b_{i}(k) u(k-i)+\sum c_{i}(k) w(k-i)+\Delta(k)
$$


where $\Delta(k)$ is the perturbation error and $y(k), u(k)$, and $w(k)$ are increments of measured process variables:

$$
\begin{aligned}
y(k) & =y_{p}(k)-y_{p}(k-1) \\
u(k) & =u_{p}(k)-u_{p}(k-1) \\
w(k) & =w_{p}(k)-w_{p}(k-1)
\end{aligned}
$$

with $y_{p}(k)$ being the process output measured at an instant $k, u_{p}(k)$ being the process input and $w_{p}(k)$ being the measurable disturbance.

According to this, the adaptive-predictive model of a $2 \times 1$ AP controller can predict the incremental process output by considering the values of the incremental variables described above. Equation (6) defines the error, $e(k)$, associated to this prediction.

$$
e(k)=y(k)-\hat{y}(k \mid k-1)
$$

This error is used to adapt the value of the AP model parameters included in Equation (2) by using error gradient algorithms, which guarantees that the error tends to be null:

$$
\begin{aligned}
& a_{i}(k)=a_{i}(k-1)+\Delta_{a i}(e(k)) \\
& b_{i}(k)=b_{i}(k-1)+\Delta_{b i}(e(k))
\end{aligned}
$$

where $\Delta_{a i}(e(k))$ and $\Delta_{b i}(e(k))$ depend on the prediction error calculated at instant $k$.

The equations presented so far indicate that adaptive-predictive control requires a consistent cause-effect relationship between process inputs and outputs so that they can be matched by the AP model. Unfortunately, industrial operations often undergo situations in which this cause-effect relationship is lost. It is in these situations when an expert control is needed so that the process can be driven back to normal operation.

Adaptive-predictive-expert (ADEX) control $[13,14]$ combines an AP control with an expert one (Figure 6) so as to provide a control solution that determines when to apply an expert control and when to use an AP one. Thus, it succeeds in optimizing the global process operation. In order to integrate the AP control with the expert control, the ADEX algorithm defines domains of operation for each of them. Expert control is based on previously-defined data and rules, that represent the system knowledge, plus the inference engine $[8,15]$. The rules are developed taking into account operator experience and trying to imitate the operations used during manual control to drive the process output from the expert domain towards the AP domain.

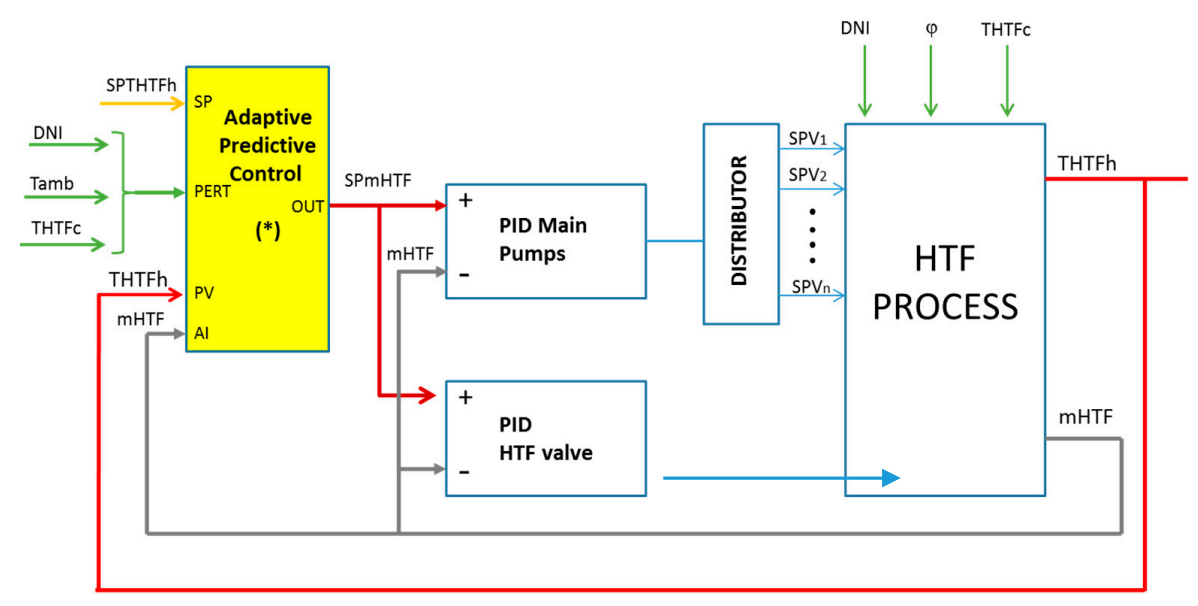

Figure 6. HTF heating process with the adaptive-predictive-expert control (ADEX) controller. 


\section{Results and Discussion}

In order to compare the response of the process to different disturbances in its input variables using different control strategies, the proposed controllers have been modelled by Simulink blocks. This paper shows the results comparison of three control algorithms:

- $\quad$ The proportional integral derivative (PID) controller, described in [5];

- $\quad$ The proportional integral derivative with feed-forward (PID-FF); and

- The adaptive-predictive-expert controller (ADEX)

The different controllers have been implemented and simulated with Simulink, using real data obtained from the plant in different seasons. Although a large number of different disturbances were introduced in order to check the response of the different controllers, in this paper the response to the following disturbances are shown:

- Sharp step in DNI. It is interesting to determine which of the proposed algorithms is the most suitable one in terms of settling time, peak temperature, and so on. On the other hand, bearing in mind the pumps, it is interesting to note the evolution of the required mass flow. As soon as an increment in DNI is produced, the mass flow has to increase in order to compensate the temperature.

- Real values for the input variables, obtained from the actual plant, called "La Africana", situated in Cordoba, Spain. These values were taken in different years and seasons: September 2010, April 2011, and July 2013. In this way, the simulations made with this set of values predict the behavior of the different algorithms proposed. Thus, the control system is tested with real parameters, as far as the DNI and HTF temperature are concerned.

Table 1 summarizes all the cases that have been taken into account for these algorithm comparisons.

Table 1. Comparison of scenarios.

\begin{tabular}{|c|c|c|c|}
\hline Scenario & PID & PID-FF & ADEX \\
\hline Sharp Step in DNI & & Figure 7 & \\
\hline Real dates from September 2010 & & Figure 9 & \\
\hline Real dates from April 2011 & & Figure 10 & \\
\hline Real dates from July 2013 & & Figure 11 & \\
\hline
\end{tabular}

\subsection{Sharp Step in DNI: Temperature Response}

The step in DNI will go from $400 \mathrm{~W} / \mathrm{m}^{2}$ to $900 \mathrm{~W} / \mathrm{m}^{2}$. This sort of disturbance may occur when the sky is full of clouds that suddenly disappear. Figure 7 shows the temperature evolution for different implemented regulators: PID, PID with feed-forward, and adaptive-expert controller.

The system controlled by the PID regulator experiments an overshoot, and although it reaches the set point, the over-temperature experimented can ruin the HTF, so it is discarded, especially if we compare it with the ADEX and feed-forward PID. The temperature spike in the case of the ADEX is around $-8{ }^{\circ} \mathrm{C}$, and with the FF-PID is around $1{ }^{\circ} \mathrm{C}$. In order to compare the proposed algorithms, the maximum HTF temperature and the settling time are considered. The error is going to be almost zero and it is not actually considered to be a differentiating parameter. Table 2 summarizes these parameters. 


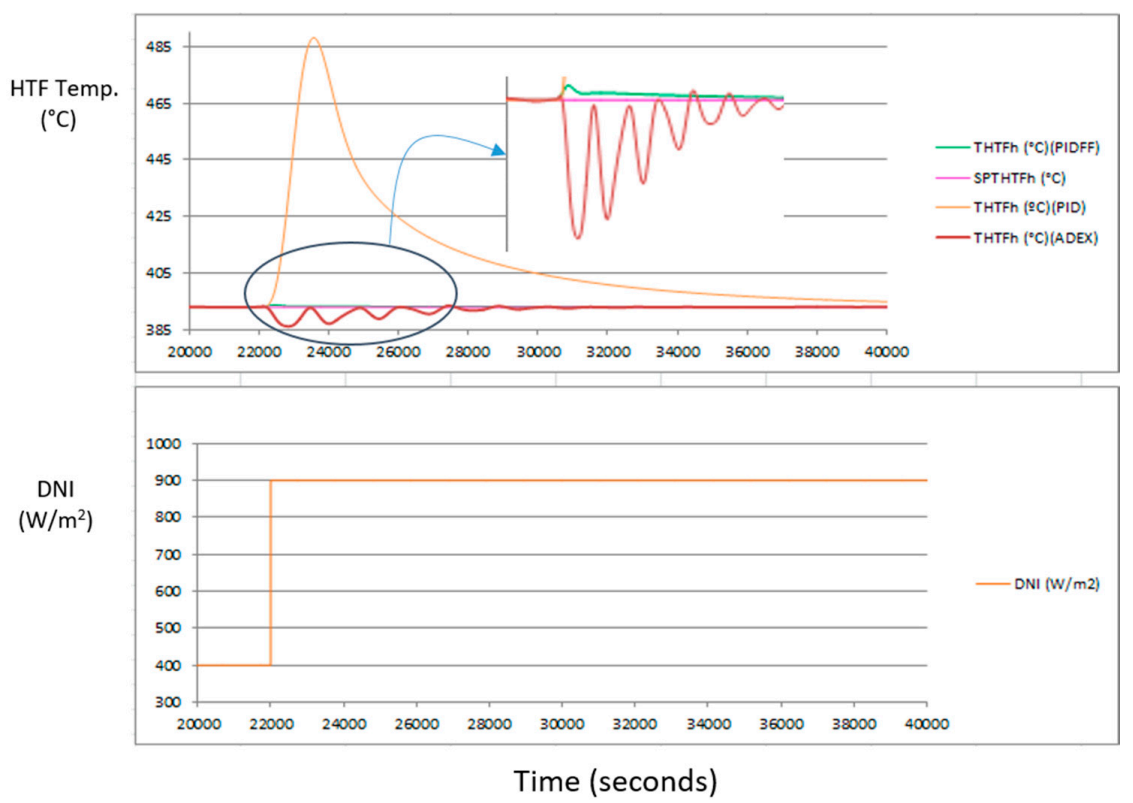

Figure 7. Heat transfer fluid temperature response to a sharp step in the DNI for different algorithms. The zoomed area shows, in detail, the overshoot and oscillations of the different regulators.

Table 2. Comparison of the algorithms.

\begin{tabular}{ccccc}
\hline Regulator & THTFhpk $\left({ }^{\circ} \mathbf{C}\right)$ & THTFh $\left({ }^{\circ} \mathbf{C}\right)$ & Settling Time $(\mathbf{s})$ & Error $(\%)$ \\
\hline PID & 488.00 & 393.01 & 33.000 & $0.0025 \%$ \\
PIDFF & 393.70 & 393.01 & 7.250 & $0.0025 \%$ \\
ADEX & 393.40 & 393.01 & 13.000 & $0.0025 \%$ \\
\hline
\end{tabular}

The PID response to a DNI sharp step is quite far from optimal, regarding not only the maximum temperature reached, but the settling time as well. Thermal fluid temperatures over $400{ }^{\circ} \mathrm{C}$ should be avoided. Additionally, the settling time is also high and if we try to reduce the high peak, the settling time will increase.

Although the behavior of the ADEX and PIDFF (PID with feed-forward) controllers is similar, as far as output temperature peak is concerned, the steady state takes longer to be reached in the ADEX controller. Once the steady state has been reached, the error is very low with all the controllers, as was expected. Although the ADEX controller shows some oscillations that correspond with a second-order system, the maximum value of these oscillations is low enough to not be worried about them.

As far as a mass flow response is concerned, it is necessary that the reference to the pumps does not oscillate too much in order to have an adequate answer, and in order to prevent their malfunction. Figure 8 shows the mass flow response when a sharp step in DNI is produced.

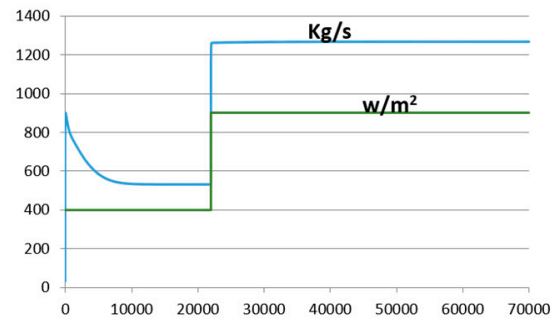

(a)

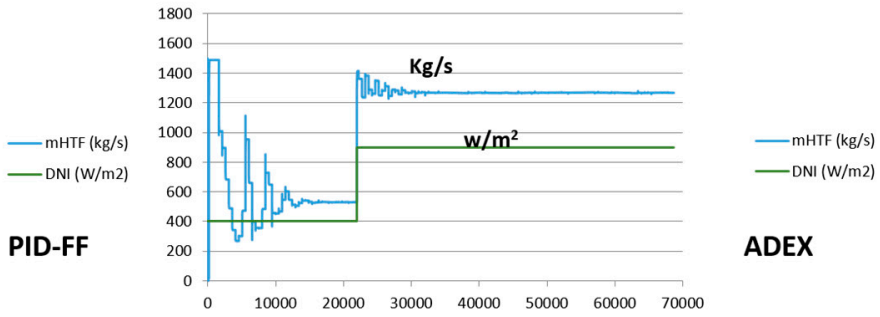

(b)

Figure 8. Mass flow response to a sharp DNI, for the PID-FF (a) and ADEX (b) controllers. 


\subsection{DNI Real Values and Temperatures in the Plant}

In order to test the proposed algorithms, real data (DNI and ambient temperature) were collected in a real solar field at the "La Africana" facilities, located in Córdoba, in the south of Spain. These data correspond to different years and seasons, in order to provide the test bench with a wide setup with different situations. The years/seasons were September 2010, April 2011, and July 2013.

In the following figures (Figures 9-11), these results are summarized. In order to check the algorithms in the steady state, the data logging starts at 20,000 s.

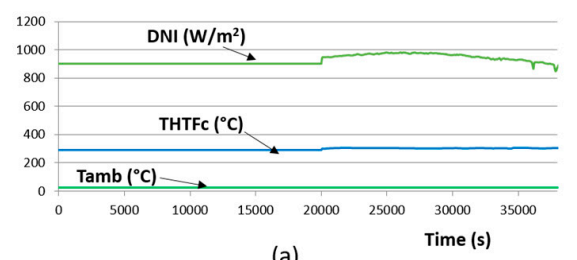

(a)

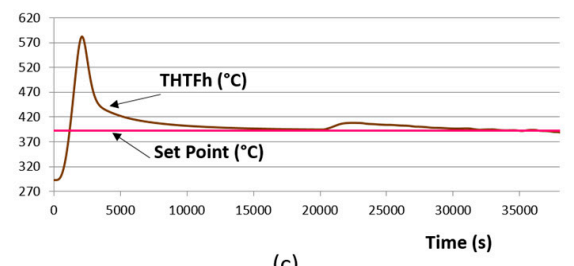

(c)

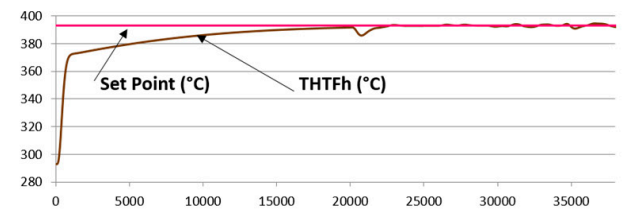

(b) Time (s)

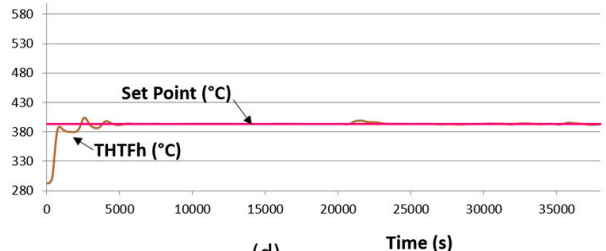

(d)

Figure 9. Results obtained for the different algorithms using real data, September 2010. DNI, ambient temperature, and HTF temperature at the solar field input (a); HTF temperature for the PID-FF (b); PID (c); and ADEX (d) regulators.

Tables 3-5 show the error average value $(\mu)$ and the error standard deviation $(\sigma)$ calculated for all the values obtained over six hours.

Table 3. Comparison of results (September 2010).

\begin{tabular}{|c|c|c|c|}
\hline \multirow{2}{*}{ Control Strategy } & \multirow{2}{*}{ Input Values } & \multicolumn{2}{|c|}{$e=S P T H T F_{h}-\mathrm{THTF}_{h}$} \\
\hline & & $\mu$ & $\Sigma$ \\
\hline PID controller & September 2010 & -1.92 & 3.27 \\
\hline PID-FF controller & September 2010 & 0.65 & 1.49 \\
\hline ADEX controller & September 2010 & -0.33 & 1.24 \\
\hline
\end{tabular}

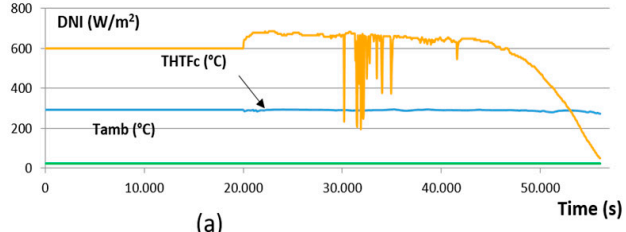

(a)

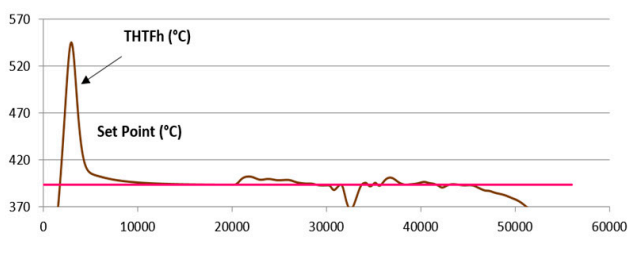

(c)
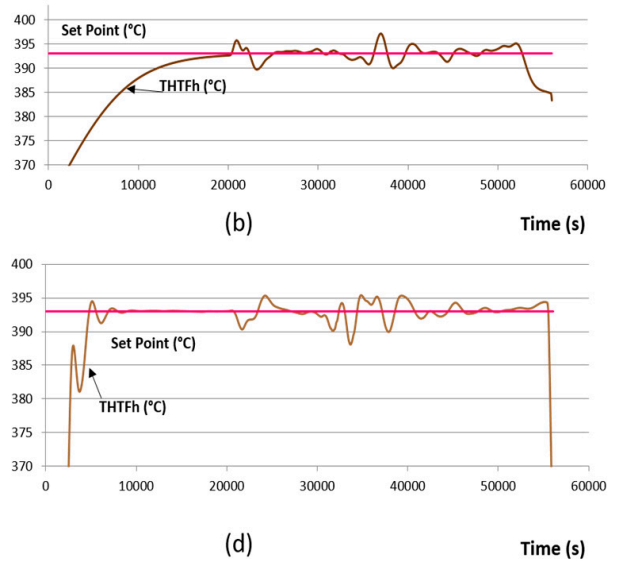

Figure 10. Results obtained for the different algorithms using real data, April 2011. DNI, ambient temperature, and HTF temperature at the solar field input (a); HTF temperature for the PID-FF (b); PID (c); and ADEX (d) regulators. 
Table 4. Comparison of results (April 2011).

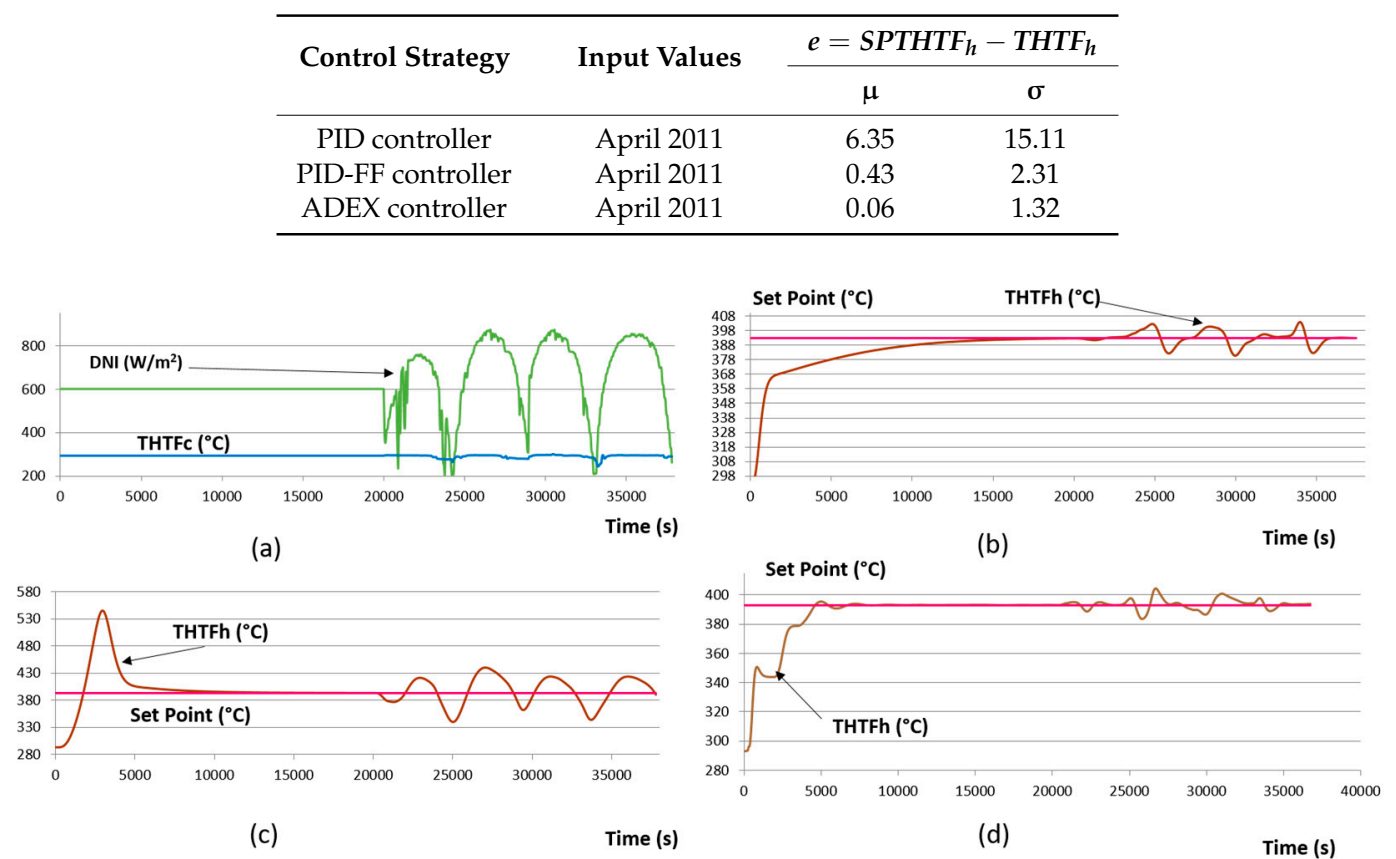

Figure 11. Results obtained for the different algorithms using real data, July 2013. DNI and HTF temperature at the solar field input (a); HTF temperature for the PID-FF (b); PID (c); and ADEX (d) regulators.

Table 5. Comparison of results (July 2013).

\begin{tabular}{|c|c|c|c|}
\hline \multirow{2}{*}{ Control Strategy } & \multirow{2}{*}{ Input Values } & \multicolumn{2}{|c|}{$e=S P T H T F_{h}-T_{H T F}$} \\
\hline & & $\mu$ & $\sigma$ \\
\hline PID controller & July 2013 & -4.06 & 25.90 \\
\hline PID-FF controller & July 2013 & -0.035 & 4.88 \\
\hline ADEX controller & July 2013 & -0.48 & 3.61 \\
\hline
\end{tabular}

\section{Conclusions}

This work has validated the suitability of the dynamic model developed in [5] to optimize the HTF heating process of a PTC thermo solar plant. This model had only been used with a PID controller, which was proven to be inadequate when rapid changes occur. In the present work, the dynamic model has been used to test other control algorithms without interfering in the operation of the plant.

The two controllers tested in this paper were a PID with feed-forward and an adaptive-predictiveexpert (ADEX) control. The behavior observed in both of them is better than that of a PID controller whenever the input variables of the process experience rapid variation. The reason for this must be found in the predictive character of the regulators tested, which does not make it necessary to wait for the output response to be produced, since this response is predicted for every variation in the process inputs.

The results obtained with the ADEX control are similar to those obtained with the PIDFF, but the former has an advantage over PID-based control strategies: changes in the dynamics of the process (dirt, aging, equipment used) do not influence its performance as much as they do in PID or PIDFF controllers. Thus, an ADEX controller will only require an initial analysis of the delays to be fully operative. From this point on, the controller itself will also deal with any changes that may appear in the dynamics of the process. 
However, there is a drawback of ADEX controllers that must be pointed out: they use a linear model, but the HTF heating process is not linear. This forces the controller's adaptive mechanism to carry out a linearization of the process for every operation point. Should rapid and frequent changes occur for that particular point, the control may give rise to inaccuracy, since its model must be constantly updated using the estimation errors generated.

Acknowledgments: This work has been subsidized through the Plan of Science, Technology and Innovation of the Principality of Asturias, (Ref: FC-15-GRUPIN14-122) and by the National Research Plan MINECO-17-TEC2016-77738-R.

Author Contributions: This paper is part of the Ph.D. Thesis of Lourdes A. Barcia, who has therefore carried out most of the work presented here. Juan Ángel Martínez was the supervisor of this work, whereas Juan Díaz and A.M. Pernía assisted Lourdes A. Barcia with Simulink simulations and regulation topics. Rogelio Peón collects the needed data in the plant.

Conflicts of Interest: The authors declare no conflict of interest.

\section{References}

1. Horizon 2020. Available online: http:/ /ec.europa.eu/programmes/horizon2020/ (accessed on 10 March 2017).

2. La inversión mundial en renovables bate su récord histórico anual. Available online: http:/ / www.expansion. com/empresas/energia/2016/03/26/56f664f9268e3ea9718b45f4.html (accessed on 17 March 2017).

3. Silver, A. 4 New ways to store renewable energy with water. IEEE Spectr. 2017, 54, 13-15. [CrossRef]

4. Luo, X.; Wang, J.; Dooner, M.; Clarke, J. Overview of current development in electrical energy storage technologies and the application potential in power system operation. Appl. Energy 2015, 137, 511-536. [CrossRef]

5. Barcia, L.A.; Menéndez, R.P.; Esteban, J.Á.M.; Prieto, M.A.J.; Ramos, J.A.M.; de Cos Juez, F.J.; Reviriego, A.N. Dynamic modeling of the solar field in parabolic trough solar power plants. Energies 2015, 8, 13361-13377. [CrossRef]

6. Prieto, M.J.; Martínez, J.Á.; Peón, R.; Barcia, L.Á.; Villegas, P.J. Optimizing the control strategy of molten-salt heat storage systems in thermal solar power plants. In Proceedings of the 2016 IEEE Industry Applications Society Annual Meeting, Portland, OR, USA, 2-6 October 2016; pp. 1-6.

7. Barcia, L.Á.; Martínez, J.Á.; Nevado, A.; Nuño, F.; Díaz, J.; Peón, R. Optimized control of the solar field in parabolic trough solar power plants. In Proceedings of the 2016 IEEE Industry Applications Society Annual Meeting, Portland, OR, USA, 2-6 October 2016; pp. 1-6.

8. Castillo, E.; Gutierrez, J.M.; Hadi, A.S. Sistemas Expertos Y Modelos de Redes Probabilísticas; Monografías de la Academia Española de Ingeniería: Madrid, Spain, 1996.

9. Hassana, M.M.; Beliveau, Y. Modeling of an integrated solar system. Build. Environ. 2008, 43, 804-810. [CrossRef]

10. Montes, M.J.; Abanades, A.; Martinez-Val, J.M. Thermofluidynamic model and comparative analysis of parabolic trough collectors using oil, water/steam, or molten salt as heat transfer fluids. J. Sol. Energy Eng. 2010, 132, 1-7. [CrossRef]

11. Burkholder, F.; Kutscher, C. Heat Loss Testing of Schott's 2008 PTR70 Parabolic Trough Receiver; National Renewable Energy Laboratory: Golden, CO, USA, May 2009.

12. Martín-Sánchez, J.M. Adaptive Predictive control System. U.S. Patent 4,197,576, 4 August 1976.

13. Martín Sánchez, J.M. Adaptive Predictive Expert Control System. U.S. Patent 6662058, 9 December 2003.

14. Martín-Sánchez, J.M.; Rodellar, J. ADEX Optimized Adaptive Predictive Controllers and Systems; From Research to Industrial Practice; Springer: Madrid, Spain, 2015; ISBN 978-3-319-09793-0.

15. Kenneth, H.R. Discrete Mathematics and Its Applications, 7th ed.; Mc Graw-Hill International Edition: New York, NY, USA, 2012; ISBN 139780077353506. 